\title{
Application of Sacrificial Layers for the Modular Micro Sensor Fabrication on a Flexible Polymer Substrate
}

\author{
Griesbach, Tim, Wurz, Marc Christopher, Rissing, Lutz \\ Institute for Micro Production Technology, Center for Production Technology \\ Leibniz Universitaet Hannover, An der Universitaet 2, 30823 Garbsen, Germany
}

\begin{abstract}
A concept for the fabrication of modular micro sensors on a flexible substrate is presented in this paper. For the fabrication of micro sensors on flexible polymer substrates, investigations on sacrificial layers are essential, since it must be possible to release the sensors at the end of the fabrication process. This paper describes the development and fabrication of an anisotropic magneto-resistance (AMR) sensor on a $5 \mu \mathrm{m}$ thick SU-8 ${ }^{\mathrm{TM}}$ layer, which is an epoxy-based photosensitive polymer. The micro sensor is fabricated on a standard Si wafer due to handling purposes during the sensor fabrication process. Initial investigations concentrated on the proof of the applicability of various sacrificial layer materials and the process compatibility of the respective techniques required for the removal of these layers. To investigate the suitability of a sacrificial layer process for the fabrication of modular micro sensors, $\mathrm{Cr}$ and $\mathrm{SiO}_{2}$ were investigated as sacrificial layer materials. Additionally, investigations on the removal of the complete Si substrate were carried out. Cr layers were fabricated within a certain thickness range by sputter deposition and electron beam evaporation. For the deposition of the $\mathrm{SiO}_{2}$ layers, a plasma enhanced chemical vapor deposition (PECVD) process was used. For the removal of the sacrificial layer with the AMR sensors on the SU-8 ${ }^{\mathrm{TM}}$ foil on top, adequate processes were developed. The etching of the Si substrate was carried out wet-chemically by caustic potash $(\mathrm{KOH})$. For etching the $\mathrm{SiO}_{2}$ layers, hydrofluoric acid (HF) and for Cr etching, the commercial etchant Selectipur® was used. Optimal process parameters were determined for etching the $\mathrm{Si}$ and $\mathrm{SiO}_{2}$ sacrificial layers, respectively.
\end{abstract}

\section{Introduction}

A new approach for the development and fabrication of micro sensors is pursued within the Collaborative Research Center (SFB) 653, which is funded by the German Research Center (DFG). To come up with genetically intelligent ("gentelligent") machine tools or components, various sensors were developed to gather user and maintenance data as well as recycling relevant information throughout the whole life cycle of the components [1]. A family of modular magnetic micro sensors covering force, strain, and magnetic property measurements has been developed so far [2, 3].

In contrast to existing micro electro-mechanical systems (MEMS) fabricated on Si substrates, this paper describes the development and fabrication of an AMR sensor using a flexible polymer as substrate material. Figure 1 depicts the design of the AMR micro sensor fabricated on a flexible substrate.

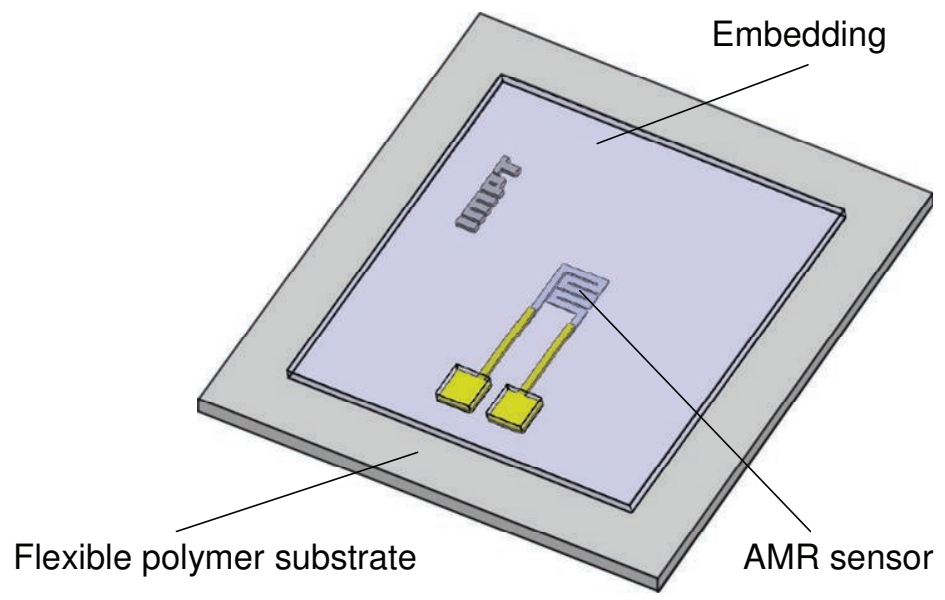

Figure 1: Design of the AMR micro sensor fabricated on a flexible substrate 
One of the main benefits of this approach is the less complex system integration later on. The application of thin flexible polymer substrates makes wafer thinning processes unnecessary, in general used at the end of the MEMS fabrication to reduce the thickness of the Si wafer [4]. For the fabrication of modular micro sensors on flexible polymer substrates, investigations on sacrificial layers are essential, since it must be possible to release the micro sensors at the end of the fabrication process. The micro sensors are fabricated on standard Si wafers due to handling purposes during the sensor fabrication process. Initial investigations concentrated on the proof of principle of applying various sacrificial layers and the respective techniques required for the removal of these layers after the front-end process.

\section{Fabrication Technologies and Challenges}

The modular micro sensors are fabricated in thin-film technology. For the deposition and patterning of the required soft magnetic as well as the conducting and insulating materials, physical vapor deposition (PVD), PECVD methods, and electroplating are combined with photolithography and etching processes. One of the major requirements for the modular micro sensor fabrication on flexible polymer substrates is that the sacrificial layer must be selectively etchable to the commonly used functional materials of the micro sensor. In case of the AMR micro sensor, no undesired chemical reactions between the functional layers of the sensor and the respective etching solution for the sacrificial layer should appear. An overview of the functional materials used for the micro sensor fabrication, the respective etchants and possible chemical reactions between the etchant and different materials is shown in Table 1.

Table 1: Overview of the functional materials used for the fabrication of the AMR micro sensor and etchants

\begin{tabular}{|c|c|c|c|}
\hline Functional Material & Component & Etchant & Also etches \\
\hline $\mathrm{Cu}$ & $\begin{array}{c}\text { Contact pads, } \\
\text { conducting leads }\end{array}$ & $\mathrm{KCN}$ & $\mathrm{Ag}, \mathrm{Au}$ \\
\hline $\mathrm{Cr}$ & Adhesion layer & $\mathrm{HClO}_{4},\left(\mathrm{NH}_{4}\right) \mathrm{Ce}\left(\mathrm{NO}_{3}\right)_{6}$ & $\mathrm{Al}$ \\
\hline $\mathrm{Au}$ & $\begin{array}{c}\text { Seed layer, } \\
\text { contact pads }\end{array}$ & $\mathrm{KCN}$ & $\mathrm{Ag}, \mathrm{Cu}$ \\
\hline $\mathrm{NiFe} 81 / 19$ & Sensing layer & $\mathrm{FeCl}_{3}$ & $\mathrm{Cu}$ \\
\hline $\mathrm{Si}$ & Substrate & $\mathrm{KOH}$ & $\mathrm{Al}, \mathrm{Cu}, \mathrm{Ag}$ \\
\hline $\mathrm{SiO}_{2}$ & Insulating layer & $\mathrm{HF}$ & $\mathrm{Ni}$ \\
\hline
\end{tabular}

Perchloric acid:

$\mathrm{HClO}_{4}$

Potassium cyanide:

$\mathrm{KCN}$

Ceric ammonium nitrate:

$\left(\mathrm{NH}_{4}\right) \mathrm{Ce}\left(\mathrm{NO}_{3}\right)_{6}$

Ferric chloride:

$\mathrm{FeCl}_{3}$

For the investigations on sacrificial layers in the micro sensor fabrication on a flexible substrate, $\mathrm{Cr}$ and $\mathrm{SiO}_{2}$ were chosen, respectively. These materials and their respective etchants nearly show no undesired chemical reactions with the functional materials of the modular micro sensor. Additionally, investigations on the removal of the complete Si substrate were carried out. In this case, the Si handling wafer serves as a sacrificial layer itself.

\section{Fabrication and Evaluation of Sacrificial Layers}

The fabrication of $\mathrm{Cr}$ layers within a certain thickness range was accomplished by sputter deposition and electron beam evaporation, respectively. For the deposition of the $\mathrm{SiO}_{2}$ layers, a PECVD process was used. The etching of the Si substrate was carried out wet-chemically by $\mathrm{KOH}$. The temperature of the etching bath was hold constant at $80^{\circ} \mathrm{C}$. For etching the $\mathrm{SiO}_{2}$ layers, $\mathrm{HF}$ and for $\mathrm{Cr}$ etching, the commercial etchant Selectipur® was used. Figure 2a shows the etching bath applied for the removal of the $\mathrm{Si}$ and $\mathrm{SiO}_{2}$ layers. The experimental set-up for the $\mathrm{Cr}$ layer etching is shown in Figure 2b. 
(a)

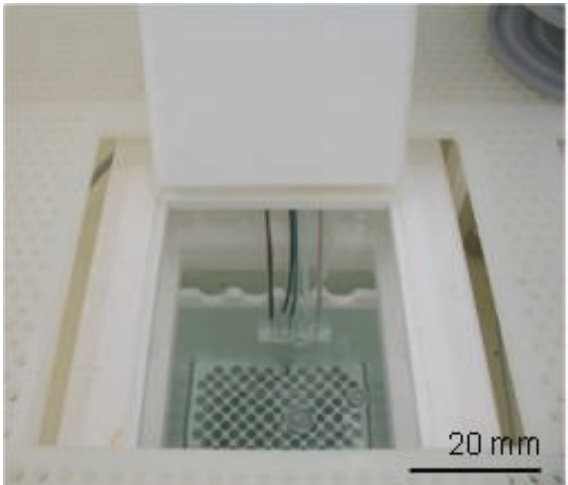

(b)

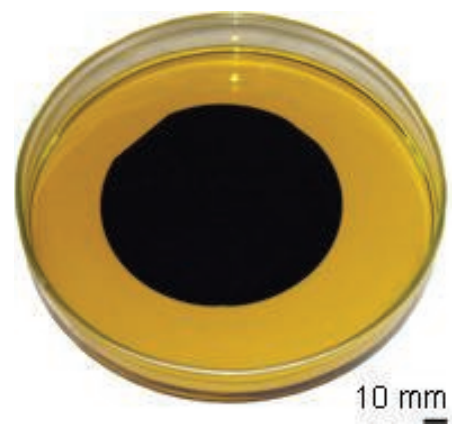

Figure 2: Experimental set-up for etching the sacrificial layers: (a) etching bath used for the removal of the $\mathrm{Si}$ and $\mathrm{SiO}_{2}$ layers; (b) experimental set-up for the $\mathrm{Cr}$ layer etching

\subsection{Fabrication and Evaluation of $\mathrm{Cr}, \mathrm{SiO}_{2}$ and $\mathrm{Si}$ Sacrificial Layers}

To investigate the applicability of $\mathrm{Cr}$ and $\mathrm{SiO}_{2}$ sacrificial layers, initial investigations were accomplished to release a $5 \mu \mathrm{m}$ thick SU-8 ${ }^{\mathrm{TM}}$ foil from the handling substrate. The corresponding fabrication sequence for $\mathrm{Cr}$ and $\mathrm{SiO}_{2}$ sacrificial layers is shown in Figure 3a.

(a)

Step 1

Step 2

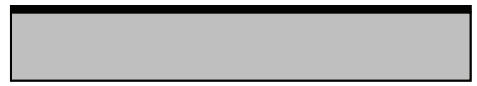

Step 3

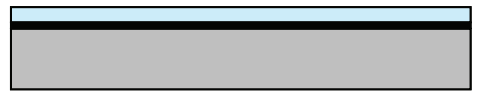

Step 4

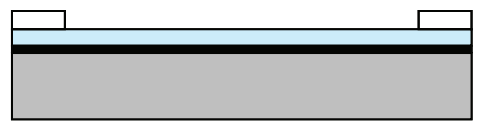

Step 5

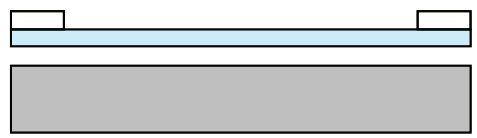

Step 6

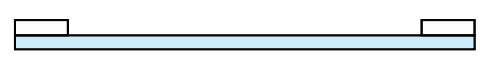

Si substrate (handling wafer)

Sacrificial layer (b)

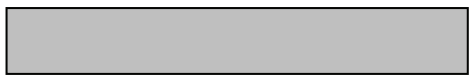

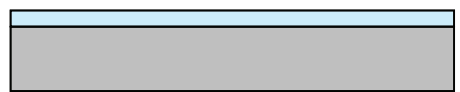
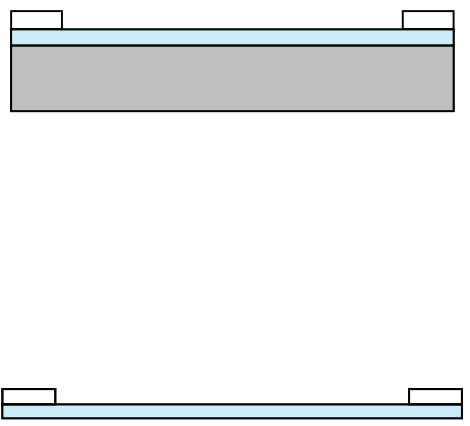

SU-8TM

Handling ring

Figure 3: Fabrication sequence to release $5 \mu \mathrm{m}$ thick SU-8 ${ }^{\mathrm{TM}}$ foils: (a) Application of a $\mathrm{Cr}$ or $\mathrm{SiO}_{2}$ sacrificial layer; (b) application of the Si handling substrate as a sacrificial layer

In the first step, the Si substrate is coated with the respective sacrificial layer (Step 2), followed by the deposition of an SU-8 ${ }^{\mathrm{TM}}$ layer by spin-coating (Step 3). A plastic ring is bonded onto the surface of the SU-8 ${ }^{\mathrm{TM}}$ layer (Step 4). The plastic ring is used due to allow for a better handling of the thin SU-8TM foil after the removal of the sacrificial layer (Step 5,6). Additional investigations on the removal of the 
complete Si substrate were carried out. In this case, the Si handling substrate serves as a sacrificial layer itself. In Figure 3b, the fabrication sequence applied to investigate $\mathrm{Si}$ sacrificial layers is shown. Compared to the experiments carried out with $\mathrm{Cr}$ and $\mathrm{SiO}_{2}$ sacrificial layers (Fig. 3a), the fabrication sequence features two differences: The fabrication process starts with the deposition of the SU-8 $8^{\mathrm{TM}}$ foil (Step 3), because the $\mathrm{Si}$ substrate serves as a sacrificial layer itself. This means, no $\mathrm{Cr}$ or $\mathrm{SiO}_{2}$ deposition is required. The removal of the handling substrate is not shown in step 5, because the Si substrate is dissolved wet-chemically by $\mathrm{KOH}$. The respective film thicknesses as well as the deposition techniques and etchants used for the investigation of $\mathrm{Cr}, \mathrm{SiO}_{2}$, and $\mathrm{Si}$ sacrificial layers are shown in Table 2. For the separation of the $\mathrm{SU}-8^{\mathrm{TM}}$ foil, adequate processes were developed for the $\mathrm{SiO}_{2}$ and $\mathrm{Si}$ sacrificial layer removal within the considered thickness range. By increasing the film thickness of the $\mathrm{SiO}_{2}$ layers from $100 \mathrm{~nm}$ to $500 \mathrm{~nm}$, the etch time decreases from 180s to 10 s caused by the increasing contact surface of the sacrificial layer in vertical direction. A reduction of the etching time was found for the Si wafers. By decreasing the wafer thickness from $500 \mu \mathrm{m}$ to $250 \mu \mathrm{m}$, the etch time is reduced from $10 \mathrm{~h}$ to $5 \mathrm{~h}$. The etching rate for $\mathrm{Si}(50 \mu \mathrm{m} / \mathrm{h})$ is thus constant, because of the unchanged contact surface of the sacrificial layer. For the investigations of $\mathrm{Cr}$ layers, no undercut of the SU-8 ${ }^{\mathrm{TM}}$ foil was observed for the investigated film thicknesses (Table 2).

Table 2: Investigated film thickness as well as deposition and etching techniques used for the evaluation of $\mathrm{Cr}, \mathrm{SiO}_{2}$, and $\mathrm{Si}$ sacrificial layers

\begin{tabular}{|c|c|c|c|c|c|}
\hline $\begin{array}{c}\text { Sacrificial } \\
\text { layer material }\end{array}$ & $\begin{array}{c}\text { Film } \\
\text { thickness }\end{array}$ & $\begin{array}{c}\text { Deposition } \\
\text { technique }\end{array}$ & Etchant & Result & Time \\
\hline $\mathrm{Cr}$ & $100 \mathrm{~nm}$ & $\begin{array}{c}\text { Sputter } \\
\text { deposition }\end{array}$ & Selectipur® & No undercut of the sacrificial layer & $3 \mathrm{~h}$ \\
\hline $\mathrm{Cr}$ & $300 \mathrm{~nm}$ & $\begin{array}{c}\text { Sputter } \\
\text { deposition }\end{array}$ & Selectipur ${ }^{\circledR}$ & No undercut of the sacrificial layer & $3 \mathrm{~h}$ \\
\hline $\mathrm{Cr}$ & $500 \mathrm{~nm}$ & $\begin{array}{c}\text { Vapor } \\
\text { deposition }\end{array}$ & Selectipur ${ }^{\circledR}$ & No undercut of the sacrificial layer & $3 \mathrm{~h}$ \\
\hline $\mathrm{SiO}_{2}$ & $100 \mathrm{~nm}$ & PECVD & $\mathrm{HF}$ & $\begin{array}{c}\text { Complete removal of the } \\
\text { sacrificial layer }\end{array}$ & $180 \mathrm{~s}$ \\
\hline $\mathrm{SiO}_{2}$ & $300 \mathrm{~nm}$ & PECVD & $\mathrm{HF}$ & $\begin{array}{c}\text { Complete removal of the } \\
\text { sacrificial layer }\end{array}$ & $30 \mathrm{~s}$ \\
\hline $\mathrm{SiO}_{2}$ & $500 \mathrm{~nm}$ & PECVD & $\mathrm{HF}$ & $\begin{array}{c}\text { Complete removal of the } \\
\text { sacrificial layer }\end{array}$ & $10 \mathrm{~s}$ \\
\hline $\mathrm{Si}$ & $250 \mu \mathrm{m}$ & - & $\mathrm{KOH}$ & $\begin{array}{c}\text { Complete removal of the } \\
\text { sacrificial layer }\end{array}$ & $5 \mathrm{~h}$ \\
\hline $\mathrm{Si}$ & $500 \mu \mathrm{m}$ & - & $\mathrm{KOH}$ & $\begin{array}{c}\text { Complete removal of the } \\
\text { sacrificial layer }\end{array}$ & $10 \mathrm{~h}$ \\
\hline
\end{tabular}

Figure 4 depicts micrographs of a thin flexible SU-8 ${ }^{\text {TM }}$ foil before the release of the Si substrate (Fig. $4 a$ ) and the SU-8TM foil after the removal of the sacrificial layer and release from the Si substrate (Fig. 4b). This result is representative for the evaluation of $\mathrm{Si}$ and $\mathrm{SiO}_{2}$ sacrificial layers.

(a)

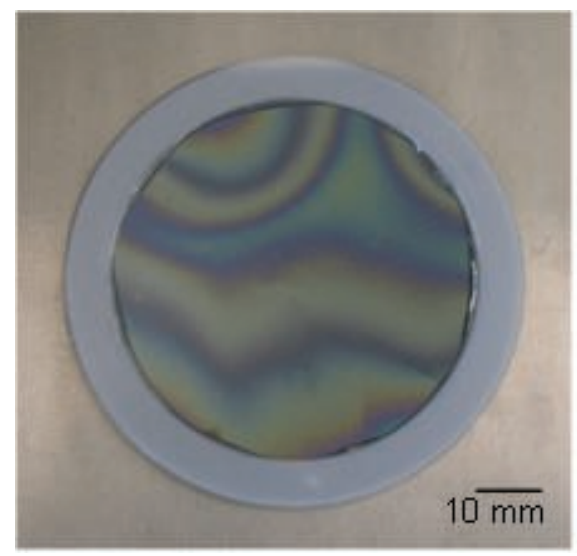

(b)

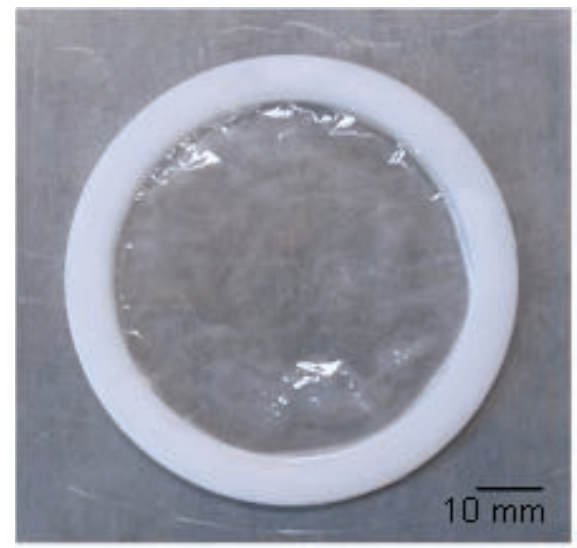

Figure 4: Micrographs of a thin flexible SU-8 ${ }^{\mathrm{TM}}$ foil: (a) before the release of the Si handling substrate; (b) after the removal of the sacrificial layer and release from the Si substrate 


\subsection{Fabrication and Evaluation of Modular Micro Sensors on a Flexible Polymer Substrate}

To proof the applicability of the process developed for the removal of the sacrificial layers, concluding investigations were accomplished to fabricate an AMR sensor on a flexible SU-8 ${ }^{\mathrm{TM}}$ layer. Based on the experimental results of the evaluation of $\mathrm{Cr}, \mathrm{SiO}_{2}$, and $\mathrm{Si}$ sacrificial layers, a $\mathrm{SiO}_{2}$ layer with a thickness of $500 \mathrm{~nm}$ was chosen. The etching of the $\mathrm{SiO}_{2}$ sacrificial layers was carried out wet-chemically by $\mathrm{HF}$. The fabrication sequence for the AMR sensor is shown in Figure 5.

(a)

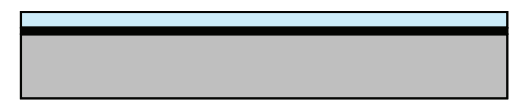

(b)

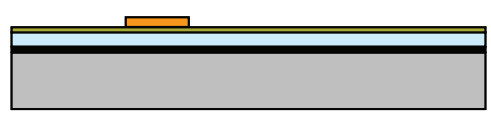

(c)

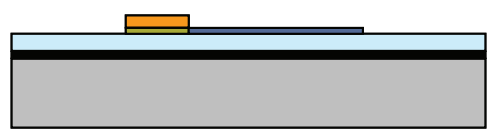

(d)

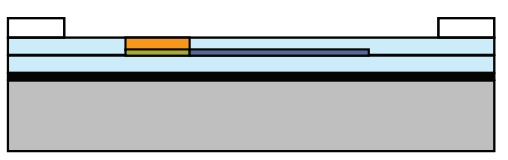

(e)

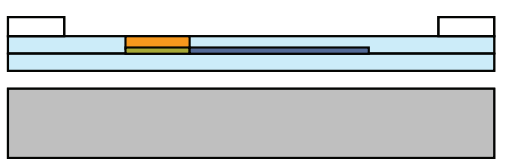

(f)

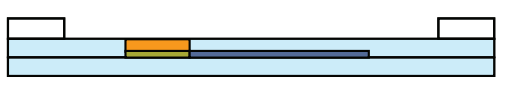

$\begin{array}{ll}\square \text { Si substrate (handling wafer) } & \mathrm{Cu} \\ & \text { Sacrificial layer } \\ \square \text { SU-8 } & \text { NiFe81/19 (sensing layer) } \\ \square \text { Au } & \square \text { Handling ring }\end{array}$

Figure 5: Fabrication sequence of an AMR sensor on a flexible polymer substrate

In the first step, the $\mathrm{SiO}_{2}$ sacrificial layer is deposited on a Si substrate, followed by the deposition of an SU-8 ${ }^{\mathrm{TM}}$ layer by spin-coating (Fig. 5a). Later, the SU-8 ${ }^{\mathrm{TM}}$ layer serves as a flexible polymer substrate itself, after the removal of the devices from the Si handling wafer. Afterwards, the micro sensor is fabricated directly on this SU-8 $8^{\mathrm{TM}}$ layer. In the next step, a $\mathrm{Cr}$ adhesion layer is sputter deposited, followed by an Au layer deposition serving as a conductive seed layer for the following electroplating process of the contact pads. To pattern the micro molds for the electroplating, a positive photoresist is used. Then, the Cu contact pads are deposited by electroplating (Fig. 5b). After the electrodeposition of the contact pads, the photoresist micro mold is stripped. A removal of the seed layer is required to inhibit short circuits. This is usually executed by ion beam etching (IBE). Afterwards, the mask for patterning the meander-shaped sensing element of the AMR sensor is also created by photolithography, using a positive-tone photoresist. The functional layer of the sensor consists of a $50 \mathrm{~nm}$ thick NiFe81/19 film, which is fabricated by sputter deposition. The patterning is based on a lift-off process (Fig. $5 \mathrm{c}$ ). The functional layers of the micro sensor are then embedded in SU-8 ${ }^{\mathrm{TM}}$. A chemically-resistant handling ring was bonded onto the surface of the SU-8 ${ }^{\mathrm{TM}}$ foil to allow a more comfortable handling of the completed 
micro sensors after the removal of the sacrificial layer (Fig. 5d). Finally, the fabricated sensors are removed from the handling $\mathrm{Si}$ wafer by wet-chemical etching of the $\mathrm{SiO}_{2}$ sacrificial layer (Fig. e, f). Figure 6 depicts micrographs of the completed AMR micro sensor on a flexible SU-8 ${ }^{\mathrm{TM}}$ substrate after the release of the handling wafer.

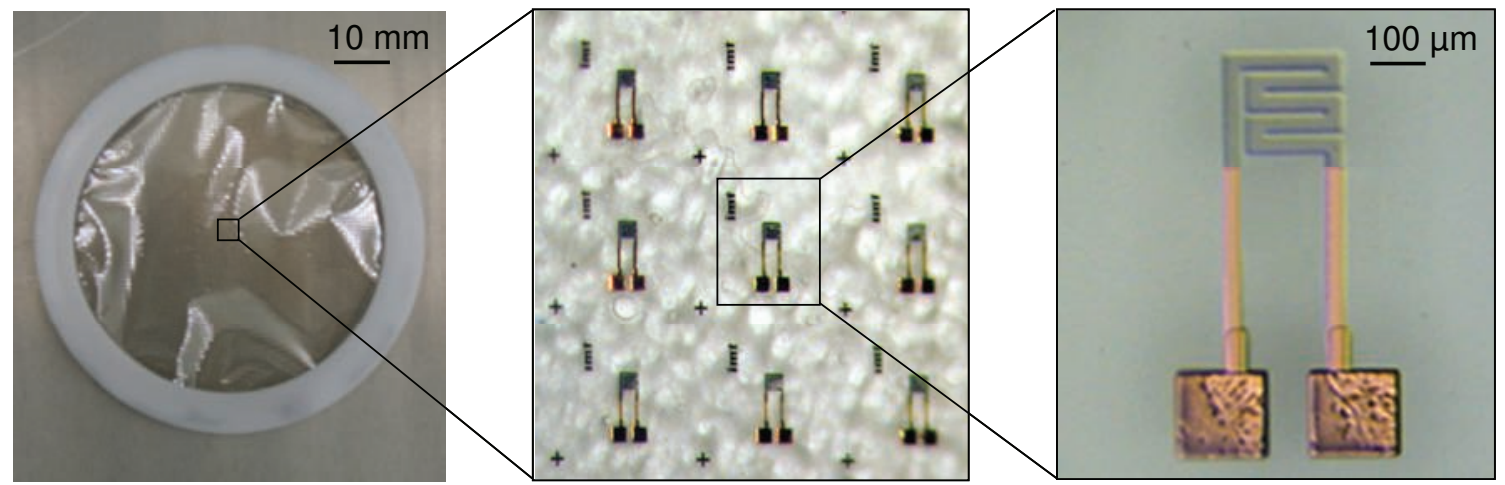

Figure 6: Micrograph of a completed AMR sensor on a flexible polymer substrate

\section{Conclusion and Outlook}

This paper demonstrates the successful fabrication of AMR sensors on a flexible polymer substrate. For the fabrication of these modular micro sensors, investigations on the applicability of $\mathrm{Cr}, \mathrm{SiO}_{2}$, and $\mathrm{Si}$ sacrificial layers were accomplished. Adequate processes were developed for the removal of $\mathrm{SiO}_{2}$ and $\mathrm{Si}$ sacrificial layers. For this purpose, investigations were conducted for the release of a $5 \mu \mathrm{m}$ thick SU-8TM foil from a Si handling substrate. Based on the results, the fabrication of first modular micro sensors was accomplished using a $\mathrm{SiO}_{2}$ sacrificial layer with a thickness of $500 \mathrm{~nm}$. Next, the electrical and magnetic properties of the AMR micro sensors fabricated on a flexible substrate will be evaluated.

\section{Acknowledgement}

This research is sponsored in part by the German Research Foundation (DFG) within the Collaborative Research Center (SFB) 653 "Gentelligent Components in their lifecycle".

\section{References}

[1] B. Denkena, K. Hasenfuß, C. Liedtke: Genetik und Intelligenz in der Produktionstechnik. Zeitschrift fuer wirtschaftlichen Fabrikbetrieb, Spur, G. (eds.), Vol.100, no. 10, pp. 569-572, 2005

[2] S. Hansen, L. Rissing, H.H. Gatzen: A Concept for a Toolbox of Components for Modular Magnetic Microsensors. Symposium on Magnetic Materials, Processes and Devices, 210th Meeting of The Electrochemical Society 2006, Cancun, Mexico, 2006, ecs transactions, Vol. 3, Issue 25, pp. 235-246, 2007

[3] T. Griesbach, L. Rissing, H.H. Gatzen: Concept for the integration of a temperature sensor in the modular, multifunctional micro sensor family. 4th I*PROMS Virtual International Conference on Innovative Production Machines and Systems, 1-14 July, 2008

[4] S. Chen, T. Kuo, H. Hu; J. Lin, S. Yu: The evaluation of wafer thinning and singulating processes to enhance chip strength, Electronic Components and Technology Conference, $55^{\text {th }}$ Proceedings, Vol. 2, pp. 1526-1530, 2005. 